\title{
Aerosol Optical Depth and the Global Brewer Network: A Study Using U.K.- and Malaysia-Based Brewer Spectrophotometers
}

\author{
WILAWAN KUMHARN \\ Sakon Nakhon Rajabhat University, Sakon Nakhon, Thailand \\ JoHn S. RimMER AND ANDREW R. D. SMEDLEY \\ The University of Manchester, Manchester, United Kingdom \\ TOH YING YING \\ The Malaysian Meteorological Department, Petaling Jaya, Malaysia \\ ANN R. WEBB \\ The University of Manchester, Manchester, United Kingdom
}

(Manuscript received 31 January 2011, in final form 16 January 2012)

\begin{abstract}
Aerosols play an important role in attenuating solar radiation reaching the earth's surface and are thus important inputs to climate models. Aerosol optical depth is routinely measured in the visible range but little data in the ultraviolet (UV) are available. In the UV range it can be determined from Langley plots of directsun measurements from the Brewer spectrophotometer (where conditions allow) and can also be determined as the residual once the ozone and sulfur dioxide have been accounted for in the extinction observed during a normal Brewer direct-sun measurement. By comparing aerosol optical depth derived from Brewer directsun data in both the United Kingdom and Malaysia, two very different locations, it is determined that while most of the existing global Brewer network could contribute to aerosol optical depth data, further analysis, such as calculation of the Ångström parameter, would be dependent on latitude and sky conditions.
\end{abstract}

\section{Introduction}

Aerosol effects are one of the major uncertainties in assessing global climate change, ecosystem processes, and human health prediction (Andreae et al. 2005; Pilewskie 2007; Satheesh and Ramanathan 2000; Sokolik and Toon 1996) because there are no effective loading controls. This is because they critically change the balance between the radiation entering and leaving the atmosphere, as well as influencing cloud formation and having direct effects on biological systems, for example, through the respiratory system. Recently, many studies have considered the importance of the aerosol's direct radiative effect in the UV area because it can significantly reduce radiation at short

Corresponding author address: Wilawan Kumharn, Department of Physics, Faculty of Science and Technology, Sakon Nakhon Rajabhat University, Sakon Nakhon 47000, Thailand. E-mail: wilawan_kumharn@snru.ac.th wavelengths (Solomon et al. 2007; WHO 2002). It was revealed that in highly polluted areas the absorption of solar UV radiation by urban anthropogenic aerosols can extensively decrease UV radiation at the earth's surface by more than 50\% (Krotkov et al. 1998; Sellitto et al. 2006). Furthermore, over nonurban areas in industrialized countries solar irradiance in the range of $280-315 \mathrm{~nm}$ (UV-B) has decreased by about $5 \%-18 \%$ since the industrial revolution owing to increasing loading of aerosols (Liu et al. 1991).

The most common instrument for ground-based measurements of aerosol optical depth (AOD) is the sun photometer. These instruments typically operate in the visible wavelength region and do not address shortwavelength UV. For example, the Cimel sun photometer (Cheymol and De Backer 2003), which is widely used in the Aerosol Robotic Network (AERONET), measures at the nominal wavelengths of 340,380, 440, 500, 675, 936, 870 , and $1020 \mathrm{~nm}$. Similarly, handheld devices like the 
Microtops II sunphotometer measure AOD at a number of individual wavelengths, using filters to determine the wavelength (Porter et al. 2001). The underlying method in each case is to make a direct-sun measurement and then apply Beer's law. In principle, any instrument that can measure wavelength-resolved direct beam radiation can be used to determine AOD.

The Brewer and Dobson spectrophotometers are currently the most common instruments for the measurement of column ozone. Because the Dobson spectrophotometer is no longer produced the Brewer has become the main instrument of choice for ground-based measurements of stratospheric ozone. The Brewer spectrophotometer was designed for automated, direct UV measurements to determine column ozone. Because it is measuring direct beam radiation, the Brewer can, in principle, determine the AOD from direct-sun measurements in the UV part of the spectrum by using Beer's law. A number of recent studies have used the Brewer spectrophotometer to determine AOD in the UV range by using the Langley plot method (LPM; see Carvalho and Henriques 2000; Cheymol and De Backer 2003; Cheymol et al. 2008; Sellitto et al. 2006; Silva and Kirchhoff 2004; Silva and Kirchhoff 2005). Surveys such as those conducted by Cheymol et al. (2006) and de la Casinière et al. (2005) have illustrated that the AOD data obtained in this way showed a good agreement (within $4 \%$ ) with other instruments. Linear extrapolation to zero air mass (i.e., the determination of the extraterrestrial radiation) was suitably constant from day to day, with typical variation of less than 3\% (Shaw et al. 1973). In addition, when aerosols were almost constant during the day, the linear regression residuals were small, resulting in highaccuracy AOD measurement. The observed uncertainty in the AOD was in the range of 0.03-0.05 (Lenoble et al. 2002). However, this method requires stable atmospheric conditions and a truly cloud-free sky. This is most likely at high mountain sites above the boundary layer, and not many places can fulfill these criteria. Furthermore, changes in instrument sensitivity over short periods can affect the results (Kazadzis et al. 2005). In addition, the uncertainty in the AOD calculation increases with an increasing air mass factor (Arola and Koskela 2004), and therefore it is best suited for an air mass factor less than 4 (Arola and Koskela 2004; Silva and Kirchhoff 2005). However, because a range of air masses is needed for the technique, the LPM is best suited to lower-latitude sites. This means that the LPM suffers from a serious location problem when considering widespread application: it becomes less viable at mid-high latitudes (Marenco 2007; Nieke et al. 1999) and where there is a lack of frequent clear-sky days.

An alternative methodology uses Beer's law to obtain AOD from each individual direct-sun ozone measurement, with the AOD being the residual attenuation after ozone and sulfur dioxide have been accounted for. This method was developed by Savastiouk (2006), and software for this application has been included in the suite of Brewer software since 2005. The method was investigated and validated by Savastiouk and McElroy (2005) and gave good agreement with the aerosol index from the Earth Probe Total Ozone Mapping Spectrometer (EP TOMS) satellite data. However, this additional application of the Brewer is neither widely recognized nor utilized. The global ozone-monitoring network has incorporated 195 Brewer instruments in 44 different countries throughout the world. They are mostly deployed to measure ozone and sulfur dioxide, but if the potential for the additional AOD data is more widely recognized, then they could play a valuable role in supplementing the existing AOD database.

Once the AOD has been established at a number of wavelengths, as would be the case with the Brewer spectrometer, it can, in principle, be used to glean further information about the aerosols. The AOD typically decreases with increasing wavelength, and this is especially so in the boundary layer that contains the majority of typical anthropogenic aerosols. The wavelength dependence of the AOD varies depending on the aerosols type and their physical and chemical characteristics and is described by the wavelength exponent $(\alpha)$ in Ångström's equations as

$$
\tau=\beta \lambda^{-\alpha},
$$

where $\tau$ is the AOD, $\beta$ is the optical depth at $\lambda=1 \mu \mathrm{m}$ (Ångström's turbidity), $\lambda$ is the wavelength $(\mu \mathrm{m})$, and $\alpha$ is the wavelength exponent. Small $\alpha$ imply large particles while large $\alpha$ indicate that the aerosol particles are fine (Eck et al. 1999).

Existing sun photometers operate across a wide wavelength range, while the Brewer wavelength range is limited. In addition, at the shortest wavelengths direct-sun measurements are challenging due to low signals. Nonetheless, $\alpha$ was determined in the UV wavelength range by using AOD obtained from LPM at Ispra, Italy, and El Arenosillo, Huelva, Spain (de la Casinière et al. 2005; Gröbner and Meleti 2004; Meleti and Cappellani 2000), with a positive $\alpha$ retrieval. In contrast, negative values of $\alpha$ have been observed by others (Cachorro et al. 1989; Jacovides et al. 2000; Kirchhoff et al. 2002; Marenco et al. 1997; Silva and Kirchhoff 2005). According to Mie scattering theory, a negative $\alpha$ would require a very large mean radius of aerosol particle and a large real part of the refractive index (Arola and Koskela 2004), which is not realistic for urban aerosol, implying that extracting $\alpha$ from the limited Brewer wavelength range is sometimes beyond the capabilities of the instrument and conditions. 
This study aims to explore the practical application and limitations of using the Brewer spectrometer to obtain AOD from the commercially available software based on Beer's law, and then to calculate $\alpha$ in different climatic conditions. Our results provide practical guidelines for the application of the existing software and should encourage the widespread uptake of this additional feature of the Brewer spectrometer, thus contributing greatly to the spatial availability of AOD and Ångström's $\alpha$ parameter data.

\section{Instrumentation}

In this study, AOD has been derived from three Brewer spectrometers operating in standard ozone-monitoring mode. Two of the instruments are in the United Kingdom and one is in Malaysia. A MKIII Brewer spectrometer has been installed on a rooftop at the University of Manchester, located in the city center area of Manchester, United Kingdom $\left(53.47^{\circ} \mathrm{N}, 2.23^{\circ} \mathrm{W}\right)$, since the summer of 2000 . The other U.K. instrument, a MKIV Brewer spectrometer, has been operational on the rooftop of the meteorological building of the University of Reading $\left(51.44^{\circ} \mathrm{N}, 0.94^{\circ} \mathrm{W}\right)$ since 2000 and, while on parkland, the motorway (M4) and light industry of the Thames valley will influence the environment of the region. Both of the instruments have been well maintained and are regularly calibrated by International Ozone Services (IOS) by intercomparison with a traveling reference instrument, which in turn is traceable to the reference triad in Toronto, Ontario, Canada, meaning that they are operating to World Meteorological Organization (WMO) Global Atmosphere Watch (GAW) standards. The AOD in Malaysia were calculated from the raw data of Malaysian Meteorological Department's (MMD's) Brewer $b$ files (the $b$ files represent the raw data). The Brewer 090 (MKII) is currently operated by the MMD, located at Petaling Jaya $\left(3.10^{\circ} \mathrm{N}, 101.65^{\circ} \mathrm{E}\right)$, Selangor, Malaysia, since October 1992. The instrument has been installed on the roof of the MMD building, located $10 \mathrm{~km}$ southwest of the capital city, Kuala Lumpur. This Brewer spectrometer has also been well maintained and regularly calibrated by IOS.

\section{Methodology}

The general principle of AOD measurement is based on Beer's law and requires measurement of the direct beam solar radiation, and then a method of distinguishing the different extinction parameters, which become more or less important depending on wavelength; for example, ozone is most important at UV-B wavelengths.

The Brewer spectrophotometer was designed for direct UV measurements to determine column ozone (Bais
1997; Fioletov et al. 2005; Gröbner et al. 1998; Savastiouk and McElroy 2005). Because it is measuring direct beam radiation, the Brewer can, in principle, determine the AOD from direct-sun measurements in the UV part of the spectrum by using Beer's law as

$I_{\lambda}=I_{0, \lambda} \exp \left(-m \tau_{\mathrm{r} \lambda}-\mu \alpha_{\lambda}, X^{\mathrm{O}_{3}}-\mu \gamma_{\lambda} X^{\mathrm{SO}_{2}}-\tau_{\mathrm{a} \lambda} m\right)$,

where $I_{0, \lambda}$ represents the count rate at wavelength $\lambda$ outside the earth's atmosphere, and is available from the Brewer calibration; $I_{\lambda}$ is count rate at wavelength $\lambda ; \mu$ is air mass factor for an ozone and sulfur dioxide layer of a height of $22 \mathrm{~km} ; \alpha_{\lambda}$ is the spectral ozone absorption coefficient; $X^{\mathrm{O}_{3}}$ is the total vertical ozone; $m$ is the air mass factor for a layer $5 \mathrm{~km}$ above the earth's surface; $\tau_{\mathrm{r} \lambda}$ is the spectral Rayleigh absorption coefficient; $\gamma_{\lambda}$ is the spectral sulfur dioxide absorption coefficient; $X^{\mathrm{SO}_{2}}$ is the total vertical sulfur dioxide; and $\tau_{\mathrm{a \lambda}}$ is the aerosol optical depth at wavelength $\lambda$, provided ozone and sulfur dioxide are known. Therefore, the AOD can be represented by

$\tau_{\mathrm{a} \lambda}=\left(\ln I_{0, \lambda}-\ln I_{\lambda}-\mu \sigma_{\lambda} X^{\mathrm{O}_{3}}-m \tau_{\mathrm{r} \lambda}-\mu \gamma_{\lambda} X^{\mathrm{SO}_{2}}\right) / m$.

In this equation, the constants are known, the air masses can be calculated from the time and location of the measurement, and column ozone and sulfur dioxide are the Brewer products. The calculation of AOD in this manner has been available via the commercially available Brewer software since 2005, but is little recognized or used. It has however been validated against LPM with correlation coefficients of $R^{2}>0.90$ for the retrieved values of AOD at all five wavelengths obtained from Brewer 172. The instrument has installed on the rooftop laboratory of the Pariser Building of The University of Manchester (Kumharn et al. 2007).

Note, however, that having investigated the commercial Brewer software, we found a fault (Kumharn et al. 2007). In calculating AOD natural logarithms should be used $\left(\log _{e}\right.$ or $\left.\ln \right)$, but the original internal Brewer software used $\log _{10}$,

$$
\text { Thus: } \mathrm{AOD}=\mathrm{AOD}_{\text {Brewersoftware }} \ln (10) .
$$

As can be seen in the above equations, the original internal Brewer software result needs to be multiplied by $\ln (10)$ to give true values. The Brewer uses direct-sun measurements to produce its products (ozone and sulfur dioxide) using a series of ratios, while not requiring absolute calibration of the direct-sun spectrum. Therefore, this finding has no impact on measurements of ozone and sulfur dioxide. Version $3.76 \mathrm{~b}$ and later of the data 
acquisition software, available from IOS, has implemented the correction, but users of previous versions of the software need to be aware of this issue. The remainder of this manuscript uses the corrected version of the Brewer software.

In this study, AOD at the five Brewer wavelengths were determined from Brewer direct-sun data for the full length of the existing datasets at the U.K. sites (2000-08 for Manchester and 2003-08 for Reading). Conditions of clear sky were determined by visual inspection of the change in individual raw counts from DS measurements at $320 \mathrm{~nm}$ versus time during the course of the day, which results in a smooth bell-shaped curve on a clear day. Days with prolonged clear periods were used for further investigations, but note that in routine operation there would be no requirement for a full clear day: any conditions suitable for a good DS measurement could provide AOD data. The air mass range was also determined for each day.

The $\alpha$ parameter is an important feature of atmospheric aerosols and is closely correlated to the size distribution of the scattering aerosol particles, and is therefore ideal for describing aerosol climatology and useful as input data for other retrieval algorithms. To calculate $\alpha$, the Volz method (VM; Volz 1974) was applied to the spectral AOD as this method can produce results in a narrowwavelength range appropriate to the Brewer (Cachorro et al. 2001). In the VM the $\alpha$ parameter is calculated by the following system of equations for each $i$ and $j$ wavelength:

$$
\begin{gathered}
\tau_{a}\left(\lambda_{i}\right)=\beta \lambda_{i}^{-\alpha}, \\
\tau_{a}\left(\lambda_{j}\right)=\beta \lambda_{j}^{-\alpha} .
\end{gathered}
$$

Using paired sets of data we then get

$$
\alpha=\ln \left[\tau_{a}\left(\lambda_{i}\right) / \tau_{a}\left(\lambda_{j}\right)\right] / \ln \left(\lambda_{j} / \lambda_{i}\right) .
$$

\section{Validations}

The validation process involves the comparison of the AOD obtained from Brewer MKIII 172 and MKIV 075 with the AOD obtained from the traveling reference Brewer MKII 017. This validation against the Brewer 017 was part of the fourth Regional Brewer Calibration Center for Europe (RBCC-E) intercomparison campaign held at the El Arenosillo Atmospheric Sounding Station of the Instituto Nacional de Técnica Aeroespacial (INTA) in Huelva, Spain, from 7 to 17 September 2009.

Brewer 017 has been operated by the IOS and checked regularly against the World Brewer Reference Triad
(BRT)-Brewer 008, 014, and 015-making it a reference source of proven stability. Analysis performed by IOS demonstrated that the ozone calculation obtained from the Brewer 017 is consistent with the BRT to within $0.8 \%$. Because of this accuracy the Brewer 017 has become the standard reference for Brewer validation worldwide, which is used in almost 400 calibrations in 36 countries (McElroy et al. 2005).

AODs for Brewer 075, 172, and 017 were retrieved from the Brewer software using standard weighting coefficients under the following conditions: first, there were clear skies; second, the ozone and sulfur dioxide from the Brewer were available and complied with the Brewer software criteria for acceptable direct-sun data; and, last, the air mass was less than 4. From the data in Fig. 1a, there was a significant positive correlation between Brewer 017 and 172 AODs, with a correlation coefficient of 0.99. As shown in Fig. 1b, it is apparent that a positive correlation was also found between Brewer 017 and 075 AODs, with a correlation coefficient of 0.99 . Figures $2 a, b$ show that there is a linear relation between the values of Brewer 172 and 075 AODs $(320 \mathrm{~nm})$ and those of the Cimel AODs $(440 \mathrm{~nm})$, with correlation coefficients of 0.90 , and 0.83 , respectively. Furthermore, the daily variation and daily average of the AODs obtained from the Cimel (440 nm) and Brewer data $(320 \mathrm{~nm})$ show the same general variation, as can be seen in the example in Figs. 3 and 4. The $\alpha$ determined using 310- and 320-nm pairs from Brewer 075, 172, and 017 were obtained under the following conditions: first, there were clear skies; second, the ozone and sulfur dioxide from the Brewer spectrometer were available and complied with the Brewer software criteria for acceptable direct-sun data; and, last, there was an air mass of less than 4 (Fig. 5). It was found that more positive $\alpha$ were obtained from using a double monochromator instrument (172).

\section{Results and discussions}

There are a number of important differences and similarities in the Brewer AOD results obtained from the United Kingdom and the tropics, as can be seen in Figs. 6-8, beginning with an illustration of the diurnal variation of clear-sky day AOD at each site within the specified air mass limit ranges.

These reflect influences of both the regional climate and the socioeconomic features of the immediate locations. There are similarities between the diurnal variation in AOD (320 nm) measured in Manchester and those found in Malaysia, as can be seen in Fig. 6. Both cities show a morning peak in AOD, which might reasonably be associated with the rush hour. AOD then reduces and is approximately constant during the middle hours of the 
(a)

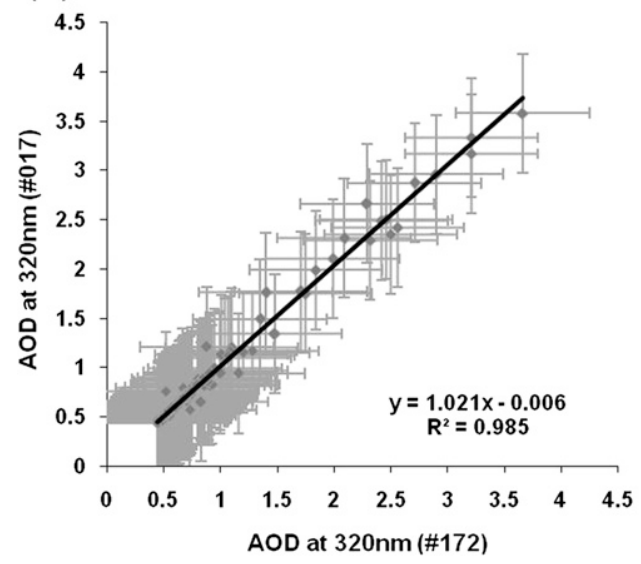

(b)

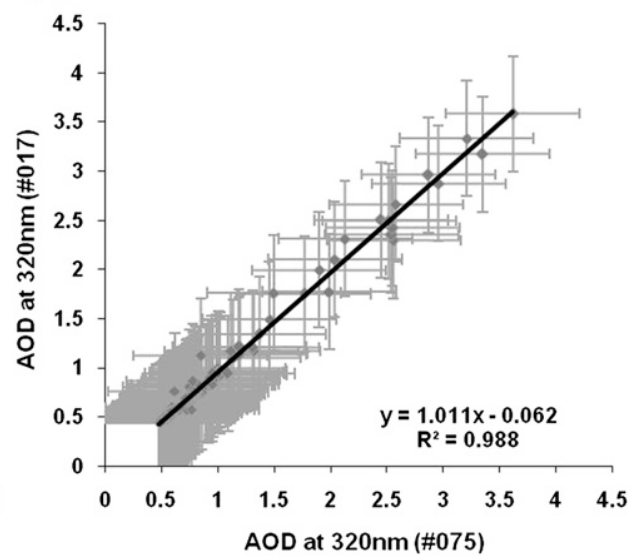

FIG. 1. (a) Scatterplot of AOD (320 nm) measurements between Brewer 017 and 172 during the fourth RBCC-E inter-Brewer comparison campaign in Huelva from 7 to 17 Sep 2009, and (b) the corresponding data for Brewer 017 against Brewer 075. The error bars represent the standard derivation of the Brewer AOD distribution.

day. There is a hint of an increase in AOD later in the afternoon, but there are little data available for the expected afternoon rush hour because air mass is too large for sensible analysis at those times. The Reading data, on the contrary, show a slightly elevated AOD in the middle of the day and no influence of any rush hour traffic. This site is found outside the main town center, in parkland surrounded by residential areas, and is not subject to the same congestion as the city center sites.

The annual variation is illustrated by using the average monthly AOD (320 nm) for all years together (2000-08 for Manchester, 2003-08 for Reading, and 1998-2007 for Malaysia). In Fig. 7, there are similarities between the
AOD patterns obtained from the two sites in the United Kingdom, which are higher in the summer compared to winter, although the magnitude of the change is greater for Manchester than Reading. On the contrary, in Malaysia monthly mean values vary little for a whole year, with marginally higher values found in July and minimum values found in November. An explanation for this is that the climate (especially day length) is similar all year, and so are the human activities in Malaysia, resulting in relatively little influence on the monthly variation in AOD. By contrast the United Kingdom has clear seasonal differences that affect both human and natural activities, and thus both sources and sinks of aerosols. (a)

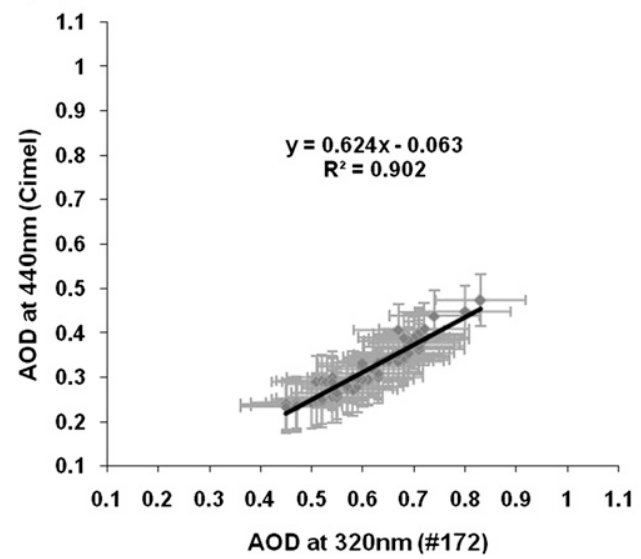

(b)

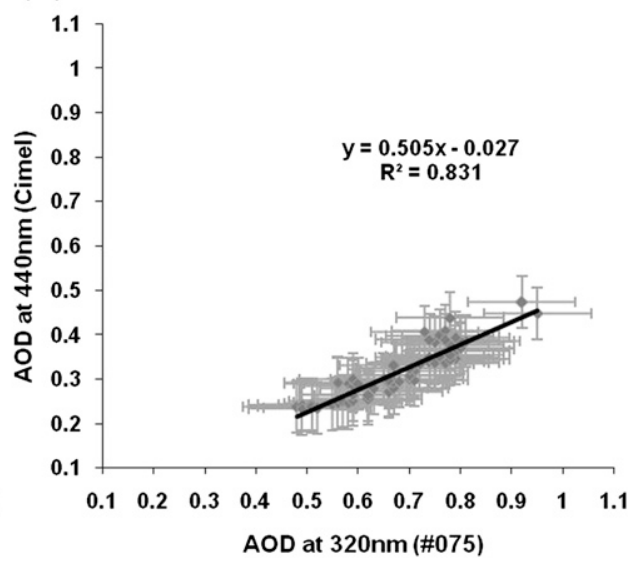

FIG. 2. (a) Scatterplot of AOD measurements between Brewer $172(320 \mathrm{~nm})$ and Cimel (440 nm) during the fourth RBCC-E inter-Brewer comparison campaign in Huelva from 7 to 17 Sep 2009, and (b) the corresponding data for Brewer $075(320 \mathrm{~nm})$ against Cimel $(440 \mathrm{~nm})$. The error bars represent the standard derivation of the Brewer AOD distribution. 


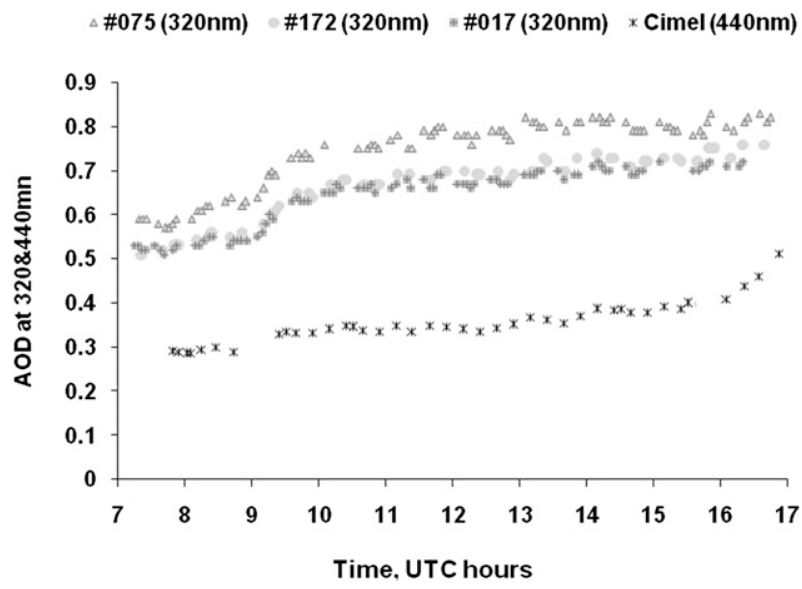

FIG. 3. Daily variation of mean value of AOD obtained from Brewer $017(320 \mathrm{~nm}), 075(320 \mathrm{~nm}), 172(320 \mathrm{~nm})$, and Cimel (440 nm) during the fourth RBCC-E inter-Brewer comparison campaign in Spain on the clear-sky day of 12 Sep 2009.

Finally, interannual variation for each site is illustrated in Fig. 8, but bear in mind that these data points are based on different numbers of clear-sky days. The similarities between the year-to-year variation in AOD (320 nm) obtained from Manchester and Reading are likely due to the effect of interannual climate variability covering the whole country (e.g., warm-cool and dry-wet years). In general, Manchester has higher AOD, which is attributed to local pollution, because Manchester is regarded as being one of the larger cities in the United Kingdom in terms of population, with a population of 464200 in the city and for the greater Manchester conurbation over 2.5 million. By contrast, Reading is an important commercial center of computer and service industries and is regarded as a large town, with a population of 235000 , and thus

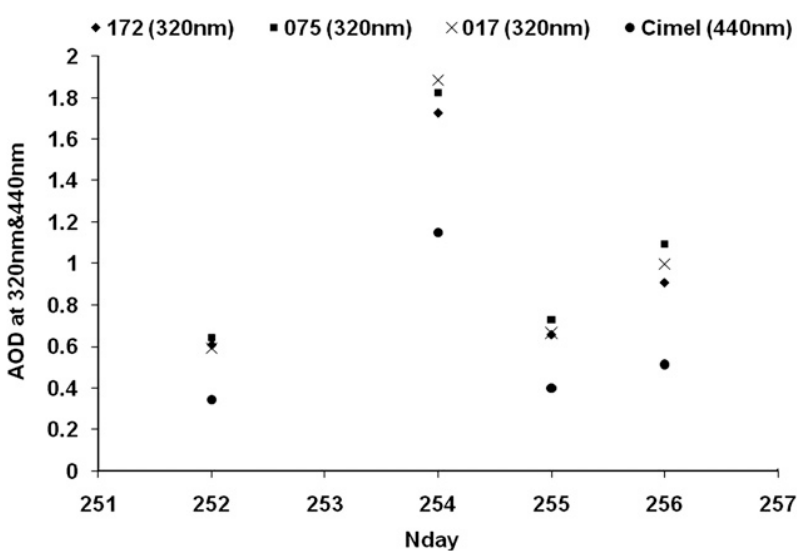

FIG. 4. Daily averages of AOD obtained from Brewer 017 $(320 \mathrm{~nm}), 075(320 \mathrm{~nm}), 172(320 \mathrm{~nm})$, and Cimel (440 nm) during the fourth RBCC-E inter-Brewer comparison campaign in El Arenosillo (2009) on the clear-sky day.

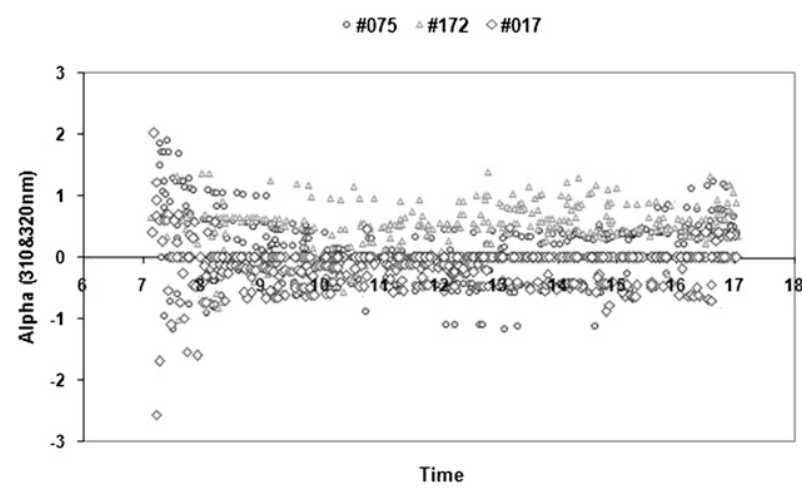

FIG. 5. The $\alpha$ using pairs 310 and $320 \mathrm{~nm}$ obtained from Brewer 075, 172, and 017 during the fourth RBCC-E inter-Brewer comparison campaign in Huelva from 7 to 17 Sep 2009.

lower levels of pollution are expected. Much higher values of AOD were found in Kuala Lumpur compared with Manchester and Reading commensurate with the size of the city (a city population of 1.8 million) and its developmental stage.

There were occasions (not included in the date ranges above) when anomalous results were achieved. These tended to be high AOD values $(>3)$ that occurred at high air mass (early morning and late afternoon), or as outliers for the day, when we assume the sky was not truly clear but did not cause an error condition in the DS measurement. Consequently, the limitation of air mass ( $\mu<4$ in the United Kingdom, and $\mu<2.2$ in Malaysia) was applied to further data analysis of AOD and $\alpha$.

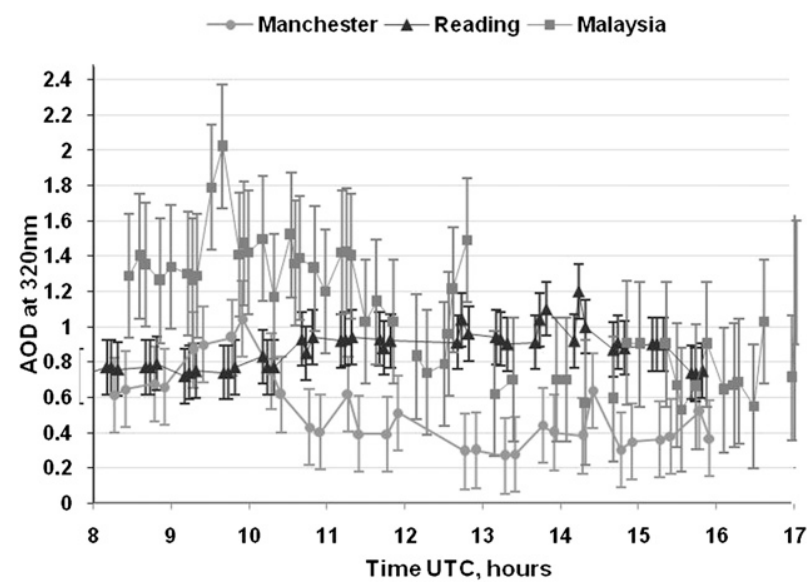

FIG. 6. The diurnal variation in AOD (320 nm) during example clear-sky days for each site and at an air mass of $>4$, on $29 \mathrm{Jul} 2007$ in Manchester and on 6 May 2008 in Reading and at an air mass in the range of 1.2-2.2 on 9 Aug 2007 in Malaysia. The error bars represent the standard error of the mean for AOD in Manchester, Reading, and Malaysia, respectively. The Malaysian data have been shifted by $8 \mathrm{~h}$ so that local noon is the same for all sites, to enable the comparison of the daily cycle of human activity. 


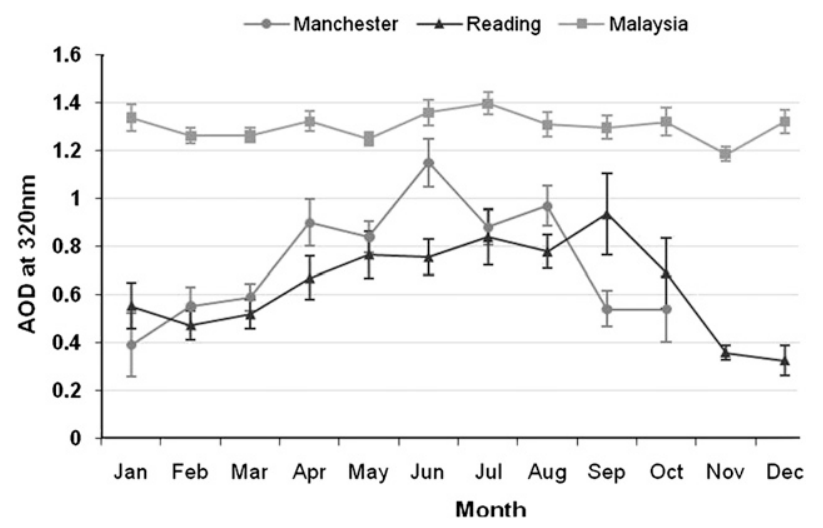

FIG. 7. The monthly variation in AOD (320 nm) during clear-sky days and an air mass of $>4$ in Manchester and Reading, and an air mass in the range of 1.2-2.2 in Malaysia. The error bars represent standard error of the mean for AOD in Manchester, Reading, and Malaysia, respectively.

Clear skies are a necessity for AOD retrieval anyway, but nominally clear days with intermittent anomalous results were excluded from the analysis.

The $\alpha$ value was determined by using VM in Manchester from 2000 to 2008, and Reading from 2003 to 2008. Data analysis was limited to clear-sky days and to an air mass less than 4. At longer wavelengths, the AOD generally decreases rapidly as wavelength increases, and one might expect this to continue into the UV. Because the VM requires measurements at only two wavelengths, there are several wavelength pairs that can be used. In principle, one would use the greatest wavelength difference across the narrow range supported by the Brewer spectrometer, but consideration must also be given to the uncertainty of individual wavelength measurements, especially at short wavelengths. Figure 9 shows all possible wavelength pairings.

From the data in Fig. 9, it can be seen that in Reading, where the single Brewer monochromator has been installed, negative $\alpha$ occurred about $90 \%-95 \%$ of the time compared with about $50 \%-75 \%$ in Manchester, where the double monochromator was operated. There are several reasons why a false negative $\alpha$ may result: it may be a consequence of calculating a difference from values that are themselves very small components as the residuals of extinction once ozone and sulfur dioxide are removed, but, more importantly, and particularly at short wavelengths, signals are low and stray light effects can be significant, especially in a single monochromator. This means that although the AOD at $320 \mathrm{~nm}$ can be validated, the extremely steep slope of ozone absorption in the Huggins band results in the correspondingly small signal at shorter wavelengths being swamped by stray light. In turn, this makes it difficult to retrieve realistic (positive) alphas under nonideal

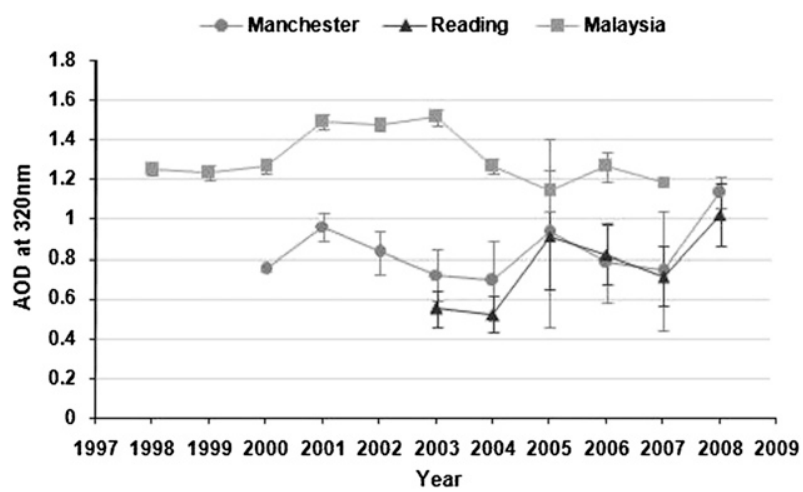

FIG. 8. The year-to-year variation in AOD (320 nm) during clear-sky days and with an air mass of $>4$ in Manchester and Reading, and an air mass in the range of 1.2-2.2 in Malaysia. The error bars represent the standard error of the mean for AOD in Manchester, Reading, and Malaysia, respectively over the (variable) number of clear-sky days included in each data point.

conditions. Furthermore, for the U.K. sites, and especially in the winter months, there is very little good-quality data because of solar zenith angle (SZA) restrictions and lack of clear skies. The higher latitude and overall cloudier conditions mean that even during the summer months physically realistic values of $\alpha$ are infrequently retrieved.

Having failed to retrieve many acceptable $\alpha$ values in the United Kingdom, the method was then applied to data from Petaling Jaya (1998-2007) to determine whether it was the general method or the conditions of measurement that were the problem. The air mass selected was in the range of 1.2-2.2 for Petaling Jaya, because it is close to the equator and the sun approaches the zenith at midday. These conditions should be optimal for avoiding the

\section{$\square$ Manchester ( $N=2133) \quad \square$ Reading $(\mathrm{N}=2983) \quad \square$ Malaysia $(\mathrm{N}=16716)$}

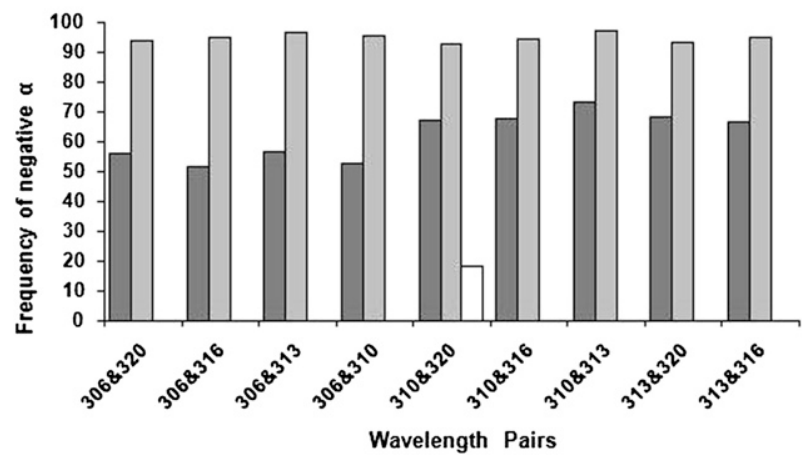

FIG. 9. Frequency of occurrence of negative $\alpha$ at nine wavelength pairs (left to right: 306 and 320, 306 and 316, 306 and 316, 306 and 310,310 and 320,310 and 316, 310 and 313, 313 and 320, and 313 and $316 \mathrm{~nm}$ ) determined by the VM in Manchester, Reading, and Malaysia (310 and $320 \mathrm{~nm}$ ). 


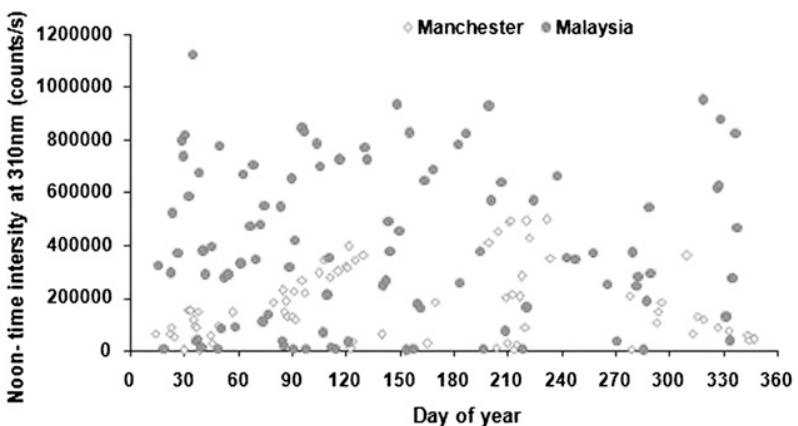

FIG. 10. Intensity of $310 \mathrm{~nm}$ at noontime taken from Brewer 172 and 090 in Manchester and Malaysia respectively during summer 2007.

signal-to-noise problem seen in the United Kingdom: the noon solar zenith angle ranges from $2.96^{\circ}$ to $48.19^{\circ}$ (an air mass of approximately 1.0-1.5) throughout the year in Petaling Jaya, compared to the $30.25^{\circ}-77.64^{\circ}$ (an air mass of approximately 1.16-4.39) in Manchester. To illustrate this we show the direct-sun measurement (raw counts) made by Brewer 172 (Manchester) and 090 (Petaling Jaya) at noontime (when respective SZAs are smallest) at $310 \mathrm{~nm}$ (Fig. 10). Note the large difference between the signals, as one might expect, and the annual cycle at Manchester compared to the year-round consistency in Malaysia.

There is no significant difference between the AOD uncertainty obtained from each of the five wavelengths, given as \pm 0.24 for Brewer 172 and \pm 0.25 for Brewer 075 (Kumharn 2010). Therefore, the selection of a wavelength pair does not make any difference to the uncertainty in $\alpha$ for each pair. However, the standard deviation obtained from 310 and $320 \mathrm{~nm}$, the widest wavelength pair that does not rely on the weakest intensity at the $306-\mathrm{nm}$ wavelength, was lower compared to other wavelength pairs at both Manchester and Reading. In addition, Arola and Koskela (2004) and Silva and Kirchhoff (2004) showed that the stray light effect for single monochromotors (MKII and MKIV) at $306 \mathrm{~nm}$ is several percent, while it reduces at longer wavelengths (as a result of the steeply increasing irradiance in this region of the spectrum). Therefore, for direct comparison with the best of the U.K. data, the wavelength pair of 310 and $320 \mathrm{~nm}$ was also used for the Malaysian data.

Initial results show that instances of negative $\alpha$ were less than $20 \%$ of the total dataset (see Fig. 11) for the years 1998-2007. Negative $\alpha$ can result from a misassignment of clear conditions (e.g., there may be some thin cirrus that do not significantly disturb ozone measurements but may disrupt the more sensitive AOD retrievals). Negative $\alpha$ values were excluded from the following analysis, which explores the viability of the remaining $\alpha$ data.

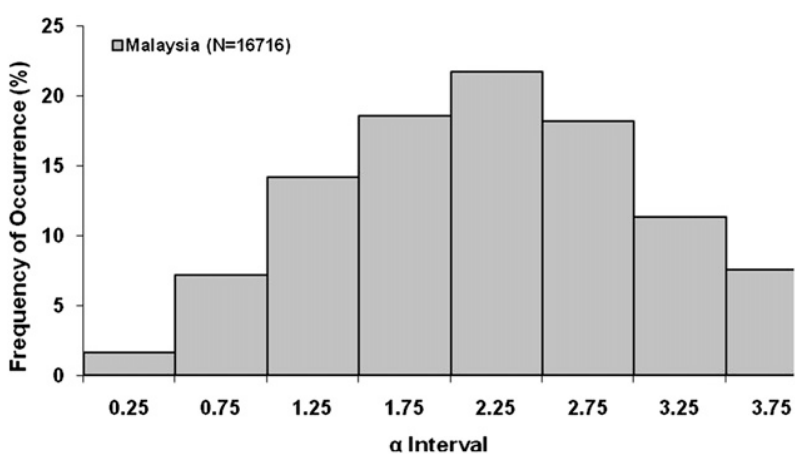

FIG. 11. Frequency of occurrence of $\alpha$ used 310- and 320-nm wavelength pair determined by the VM between 1998 and 2007 in Malaysia.

Figure 11 shows the frequency distribution of $\alpha$, which indicates the associated distribution of aerosol size in the atmosphere of Petaling Jaya. The highest frequency is for $\alpha$ interval of $2.0-2.5$ at $21.7 \%$, while the smallest $\alpha$ bin (between 0.0 and 0.5 ) has a frequency $<5 \%$. Larger values of $\alpha$ indicate relatively small particles while smaller $\alpha$ approaching 0 suggest very large particles. On the question of $\alpha$, this study found that aerosol particles show a clear domination by the fine mode, which is associated with a small particle size in the range of $0.01-1 \mu \mathrm{m}$. Such fine mode particles are associated with urban pollution, mainly from road traffic and industrial and anthropogenic activities as the major sources of aerosol emission. These findings are consistent with those of Afroz et al. (2003) and Awang et al. (2000), who found that the sources of aerosol in Malaysia were mainly due to transportation, factories, and biomass burning.

It is clear that extracting $\alpha$ from Brewer data is not always reliable. The most promising retrievals require high signal-to-noise ratios and truly cloud-free conditions. These are best achieved at low SZA and with a double monochromator, plus direct observation of clear-sky conditions. The best choice of wavelength pairing must also be considered to try and reduce the uncertainty in $\alpha$ because the largest fluctuations in the $\alpha$ parameter take place when nearby wavelengths are used. In addition, there is also a large degree of scatter, and many individual values are unrealistic. The standard derivation obtained from 310 and $320 \mathrm{~nm}$, the widest wavelength pair that does not rely on the intensity-challenged $306 \mathrm{~nm}$, was lower compared to other wavelength pairs at both Manchester and Reading.

\section{Conclusions}

AOD values have been obtained from Brewer spectrophotometers at UV-B wavelengths on clear-sky days at 
sites in the United Kingdom and the tropics. Both the underlying climate and the sources of aerosol are expected to differ considerably between the United Kingdom and tropics, producing quite different AOD values. The results are supported by independent data and also agree qualitatively with what one might expect based on general argument about climate and human activity. The Brewer wavelengths are, however, spread over a very limited range, which reduces the confidence in deriving $\alpha$. This is particularly so when the data at the shortest wavelengths is in doubt, as is the case for the Reading data, in particular, and much of the U.K. data in general. This is because at large air masses the UV signal at short wavelengths is very low. Added to this the single monochromator instruments (as at Reading) are the most susceptible to stray light problems, which further reduces confidence in the shorter wavelength data, thus reducing a very narrow wave band range even further. After attempting to determine $\alpha$ for all sites it became apparent that useful data were only available on a regular basis from the tropical site. At the U.K. sites many individual analyses produced negative values of $\alpha$ for the UV, which are difficult to reconcile with a physical explanation. Given the limited clear-sky occasions, and the large air masses during much of the year, it was not deemed possible to reliably retrieve $\alpha$ from the Brewer in these conditions, when operating in standard, unattended monitoring mode. In Malaysia, $\alpha$ was more reliably calculated for high-intensity direct-sun measurement and truly cloud-free conditions. Aerosol particles there show a clear domination by the fine mode. This domination is probably caused by urban pollution, mainly from road traffic and industrial and anthropogenic activities.

The work with $\alpha$ shows the limitations of the techniques with the Brewer measurement taken at low signal to noise or less than a perfectly clear sky. Thus, for example, highlatitude stations may not produce data of sufficient quality to allow further analysis of AOD in the UV. However, valid AOD values, if only at $320 \mathrm{~nm}$, determined via the new Brewer software can be retrieved whenever good direct-sun measurements are possible. These discrete measurements require stable, cloud-free conditions in the vicinity of the direct sun for less than $5 \mathrm{~min}$. This is a great improvement on the previously reported LPM, which, while theoretically robust, is not a viable proposition in many climates because it requires stable, cloud-free atmospheric conditions for at least a half-day.

Acknowledgments. W. Kumharn would like to thank the Royal Thai Government for its financial support for the duration of this work. The authors thank Department for Environment, Food and Rural Affairs
(DEFRA) who kindly funded the operation of Brewer spectrophotometer 075 throughout the duration of this study, under Grant CPEG35 (Baseline Measurements and Analysis of U.K. Ozone and UV). The authors also would like to thank the MMD for the raw $b$ file obtained from Brewer spectrophotometer 090.

\section{REFERENCES}

Afroz, R., M. N. Hassan, and N. A. Ibrahim, 2003: Review of air pollution and health impacts in Malaysia. Environ. Res., 92, 71-77.

Andreae, M. O., C. D. Jones, and P. M. Cox, 2005: Strong presentday aerosol cooling implies a hot future. Nature, 435, 11871190.

Arola, A., and T. Koskela, 2004: On the sources of bias in aerosol optical depth retrieval in the UV range. J. Geophys. Res., 109, D08209, doi:10.1029/2003JD004375.

Awang, M. B., A. B. Jaafar, A. M. Abdullah, M. B. Ismail, M. N. Hassan, R. Abdullah, S. Johan, and H. Noor, 2000: Air quality in Malaysia: Impacts, management issues and future challenges. Respirology, 5, 183-196.

Bais, A. F., 1997: Absolute spectral measurements of direct solar ultraviolet irradiance with a Brewer spectrophotometer. Appl. Opt., 36, 5199-5204.

Cachorro, V. E., M. J. Gonzalez, A. M. De Frutos, and J. L. Casanova, 1989: Fitting Angstrom's formula to spectrally resolved aerosol optical thickness. Atmos. Environ., 23, 265270.

— R. Vergaz, and A. M. De Frutos, 2001: A quantitative comparison of $\AA$ turbidity parameter retrieved in different spectral ranges based on spectroradiometer solar radiation measurements. Atmos. Environ., 35, 5117-5124.

Carvalho, F., and D. Henriques, 2000: Use of Brewer ozone spectrophotometer for aerosol optical depth measurements on ultraviolet region. Adv. Space Res., 25, 997-1006.

Cheymol, A., and H. De Backer, 2003: Retrieval of the aerosol optical depth in the UV-B at Uccle from Brewer ozone measurements over a long time period 1984-2002. J. Geophys. Res., 108, 4800, doi:10.1029/2003JD003758.

,-- W. Josefsson, and R. Stübi, 2006: Comparison and validation of the aerosol optical depth obtained with the Langley plot method in the UV-B from Brewer Ozone Spectrophotometer measurements. J. Geophys. Res., 111, D16202, doi:10.1029/2006JD007131.

, L. Gonzalez Sotelino, K. S. Lam, J. Kim, V. Fioletov, H. De Backer, and A. M. Siani, 2008: Intercomparison of aerosol optical depth from Brewer ozone spectrophotometers and CIMEL sunphotometers measurements. Atmos. Chem. Phys., 9, 733-741.

de la Casinière, A., and Coauthors, 2005: Comparative measurements of total ozone amount and aerosol optical depth during a campaign at El Arenosillo, Huelva, Spain. Ann. Geophys., 23, 3399-3406.

Eck, T. F., B. N. Holben, J. S. Reid, O. Dubovik, A. Smirnov, N. T. O'Neill, I. Slutsker, and S. Kinne, 1999: Wavelength dependence of the optical depth of biomass burning, urban, and desert dust aerosols. J. Geophys. Res., 104 (D24), $31333-$ 31349.

Fioletov, V. E., J. B. Kerr, C. T. McElroy, D. I. Wardle, V. Savastiouk, and T. S. Grajnar, 2005: The Brewer reference triad. Geophys. Res. Lett., 32, L20805, doi:10.1029/2005GL024244. 
Gröbner, J., and C. Meleti, 2004: Aerosol optical depth in the UVB and visible wavelength range from Brewer spectrophotometer direct irradiance measurements: 1991-2002. J. Geophys. Res., 109, D09202, doi:10.1029/2003JD004409.

—, D. I. Wardle, C. T. McElroy, and J. B. Kerr, 1998: Investigation of the wavelength accuracy of Brewer spectrophotometers. Appl. Opt., 37, 8352-8360.

Jacovides, C. P., M. D. Steven, and D. N. Asimakopoulos, 2000: Spectral solar irradiance and some optical properties for various polluted atmospheres. Sol. Energy, 69, 215-227.

Kazadzis, S., A. Bais, N. Kouremeti, E. Gerasopoulos, K. Garane, M. Blumthaler, B. Schallhart, and A. Cede, 2005: Direct spectral measurements with a Brewer spectroradiometer: Absolute calibration and aerosol optical depth retrieval. Appl. Opt., 44, 1681-1690.

Kirchhoff, V. W. J. H., A. A. Silva, and D. K. Pinheiro, 2002: Wavelength dependence of aerosol optical thickness in the UV-B band. Geophys. Res. Lett., 29, 1620, doi:10.1029/ 2001 GL014141.

Krotkov, N. A., P. K. Bhartia, J. R. Herman, V. Fioletov, and J. Kerr, 1998: Satellite estimation of spectral surface UV irradiance in the presence of tropospheric aerosols 1 . Cloud-free case. J. Geophys. Res., 103 (D8), 8779-8793.

Kumharn, W., 2010: Assessing the role of Brewer spectrophotometer in determining aerosol optical properties in the UK and tropics. Ph.D. thesis, The University of Manchester, $226 \mathrm{pp}$.

— J. S. Rimmer, and A. R. Webb, 2007: Comparison of methodologies for determining aerosol optical depth in the UVB at Manchester from Brewer MKIII spectrophotometer. 10th WMO-GAW Brewer Users Group Workshop, Northwich, UK, WMO-GAW, 31.

Lenoble, J., and Coauthors, 2002: Retrieval of the ultraviolet aerosol optical depth during a spring campaign in the Bavarian Alps. Appl. Opt., 41, 1629-1639.

Liu, S. C., S. A. McKeen, and S. Madronich, 1991: Effect of anthropogenic aerosols on biologically active ultraviolet radiation. Geophys. Res. Lett., 18, 2265-2268.

Marenco, F., 2007: On Langley plots in the presence of a systematic diurnal aerosol cycle centered at noon: A comment on recently proposed methodologies. J. Geophys. Res., 112, D06205, doi:10.1029/2006JD007248.

_ V. Santacesaria, A. F. Bais, D. Balis, A. Di Sarra, A. Papayannis, and C. Zerefos, 1997: Optical properties of tropospheric aerosols determined by lidar and spectrophotometric measurements (Photochemical Activity and Solar Ultraviolet Radiation campaign). Appl. Opt., 36, 6875-6886.

McElroy, C. T. and E. W. Hare, Eds., 2005: The ninth biennial WMO consultation on Brewer ozone and UV spectrophotometer operation calibration and data reporting. GAW Rep. 175, 69 pp. [Available online at ftp://ftp.wmo.int/Documents/ PublicWeb/arep/gaw/gaw175_9thbrewer.pdf.]
Meleti, C., and F. Cappellani, 2000: Measurements of aerosol optical depth at Ispra: Analysis of the correlation with UV-B, UV-A, and total solar irradiance. J. Geophys. Res., 105 (D4), 4971-4978.

Nieke, J., B. Pflug, and G. Zimmermann, 1999: An aureolecorrected Langley-plot method developed for the calibration of HiRES grating spectrometers. J. Atmos. Sol. Terr. Phys., 61, 739-744.

Pilewskie, P., 2007: Climate change: Aerosols heat up. Nature, 448, 541-542.

Porter, J. N., M. Miller, C. Pietras, and C. Motell, 2001: Ship-based sun photometer measurements using microtops sun photometers. J. Atmos. Oceanic Technol., 18, 765-774.

Satheesh, S. K., and V. Ramanathan, 2000: Large differences in tropical aerosol forcing at the top of the atmosphere and Earth's surface. Nature, 405, 60-63.

Savastiouk, V., 2006: Improvements to the direct-sun ozone observations taken with the Brewer spectrophotometer. Ph.D. thesis, York University, 147 pp. [Available online at http:// www.esrl.noaa.gov/gmd/grad/neubrew/docs/publications/ VladimirSavastiouk_PhD_thesis.pdf.]

—, and C. McElroy, 2005: Brewer spectrophotometer total ozone measurements made during the 1998 Middle Atmosphere Nitrogen Trend Assessment (MANTRA) campaign. Atmos.-Ocean, 43, 315-324.

Sellitto, P., A. d. Sarra, and A. M. Siani, 2006: An improved algorithm for the determination of aerosol optical depth in the ultraviolet spectral range from Brewer spectrophotometer observations. J. Opt., 10A, 849-855.

Shaw, G. E., J. A. Reagan, and B. M. Herman, 1973: Investigations of atmospheric extinction using direct solar radiation measurements made with a multiple wavelength radiometer. J. Appl. Meteor., 12, 374-380.

Silva, A. A., and V. W. J. H. Kirchhoff, 2004: Aerosol optical thickness from Brewer spectrophotometers and an investigation into the stray-light effect. Appl. Opt., 43, 2484-2489.

_ spectrophotometer to determine the aerosol optical thickness at several sites. Energy, 30, 1643-1647.

Sokolik, I. N., and O. B. Toon, 1996: Direct radiative forcing by anthropogenic airborne mineral aerosols. Nature, 381, 681683.

Solomon, S., D. Qin, M. Manning, M. Marquis, K. Averyt, M. M. B. Tignor, H. L. Miller Jr., and Z. Chen, Eds., 2007: Climate Change 2007: The Physical Sciences Basis. Cambridge University Press, 996 pp.

Volz, F. E., 1974: Economical multispectral sun photometer for measurements of aerosol extinction from $0.44 \mathrm{~nm}$ to $1.6 \mathrm{~nm}$ and precipitable water. Appl. Opt., 13, 1732-1733.

WHO, 2002: The world health report 2002-Reducing risks, promoting healthy life. $230 \mathrm{pp}$. [Available online at http:// www.who.int/whr/2002/en/whr02_en.pdf.] 